\title{
LA JURISPRUDENCIA DE DERECHOS HUMANOS EN LA ARGENTINA
}

\author{
Adrian Manzi ${ }^{1}$ \\ Universidad Nacional de San Luis, Argentina
}

http://dx.doi.org/10.5209/rev_NOMA.2012.41780

\begin{abstract}
Resumen.- En este trabajo se citarán los fallos de los tribunales provinciales, nacionales y de la Comisión Interamericana de Derecho Humanos que han establecido jurisprudencia tanto a nivel nacional como a nivel internacional de los derechos humanos en el marco de adhesión, de aprobación; de ratificación y de entrada en vigor a los tratados internacionales de derecho humanos en la Constitución Nacional Argentina. Hay una invocación al sistema de derecho a través de un saber hacer y un conocer, que hace de la sociedad argentina sea caracterizada por los órdenes de un discurso jurídico que enumera y clasifica, controla y codifica, narra y sentencia, tipifica y condena o absuelve, en tanto derecho humano. Más allá de una posible o evidente violación a un derecho ya establecido, la dinámica social exige, mediante un fundamentado conocimiento, demandar a la estructura del derecho que otorgue subjetividad a los individuos en tanto sujeto de derechos en caso de ser éstos han sido ultrajados y que dejan en estado de desvalimiento jurídico, y por ende político, a individuos.
\end{abstract}

Palabras Clave.- reforma constitucional, jurisprudencia, fallos, garantías

Abstract.- In this work there will be mentioned the failures of the provincial, national and of the Inter-American Commission of Law Human beings courts that have established jurisprudence so much national as worldwide of the human rights in the frame of adhesion, of approval; of ratification and of entry into force to the international agreements of right human beings in the National Constitution Argentina. An invocation is to the system of right across one to be able to make and one know, that it does of the Argentine company is characterized by the orders of a juridical speech that enumerates and classifies, it controls and codifies, narrates and pronounces, typifies and condemns or absolves, while human right. Beyond a possible or evident violation to an already established right, the social dynamics demands, by means of a based knowledge, to demand to the structure of the right that it grants subjectivity to the individuals while subject of rights in case of being these they have been ultrajados and that they leave in condition of juridical helplessness, and for ende politician, individuals.

Keywords.- constitutional reform, jurisprudence, failures, guarantees

\section{Introducción}

Como dijimos, se citarán los fallos de los tribunales provinciales y nacionales y de la Corte Suprema de Justicia de la Nación Argentina que han establecido jurisprudencia de los derechos humanos en el marco de entrada en vigor de los tratados internacionales incorporados a la Constitución Nacional Argentina.

Como hemos ido desarrollando a lo largo de trabajos anteriores (Parisí, Manzi;

\footnotetext{
${ }^{1}$ Catedrático de Psicología Política - Universidad Nacional de San Luis, Integrante Proyecto de Investigación Psicología Política.
} 
2012), colocaremos aquellos aspectos que nos parecen más relevantes en cuanto al tema que nos preocupa, completando con datos pertinentes como lo es la situación general de los argentinos, para despuntar así el tejido que respecta a la vivencia de la situación de los derechos humanos en Argentina.

Las organizaciones no gubernamentales han cumplido, según lo investigado, una función de vital importancia para el restablecimiento del goce de la dignidad de vida en el Estado de Derecho. Tanto es así que han logrado ser reconocidas, no sólo simbólicamente por los poderes legislativo, ejecutivo y la sociedad en general, sino porque han tenido injerencia directa sobre las actuaciones y decisiones que ha tomado el poder judicial en materia de derechos humanos.

La tensión cultural y política provocada por la pauperización en la vida institucional argentina por corrupción e ineficiencia durante los '70, '80 y '90, en coyuntura con las ratificaciones de los tratados de 1994, en consonancia con los Planes de Ajuste Estructurales aplicados desde 1991 hasta 1999, y una precaria gobernabilidad representativa durante estas tres décadas señaladas, se orientó a plantearle a la justicia demandas por la incompatibilidad y contradicción entre lo firmado ante la comunidad internacional en materia de derechos humanos y el nivel de dignidad de vida de la sociedad argentina. No todo fue llevado a la justica a partir de entonces, pero al sistema jurídico se le comenzó a demandar cada vez más accionar y más intervención en políticas públicas y en materia de salud y seguridad, identidad sexual, por nombrar sólo algunos. Las organizaciones no gubernamentales tuvieron mucho que ver en este aumento de demanda.

\section{Historia y característica de las Reformas Constitucionales en Argentina}

La Reforma Constitucional de 1994 concluyó con la jura de la Constitución Argentina con un texto ordenado en el Palacio de San José, Paraná, Provincia de Entre Ríos, produjo un cambio verdaderamente significativo en la dimensión judicial de la sociedad argentina. Los Tratados que fueron firmados son: La Declaración Americana de los Derechos y Deberes del Hombre; la Declaración Universal de los Derechos Humanos; la Convención Americana sobre Derechos Humanos; el Pacto Internacional de Derechos Económicos, Sociales y Culturales; el Pacto Internacional de Derechos Civiles y Políticos y su Protocolo Facultativo, la Convención sobre la Prevención y la Sanción del Delito del Genocidio; la Convención Internacional sobre la Eliminación sobre todas las formas de Discriminación Racial; la Convención sobre la Eliminación sobre todas las formas de Discriminación contra la Mujer; la Convención contra la Tortura y Otros Tratos o Penas Crueles, Inhumanos o Degradantes; la Convención sobre los Derechos del Niño. ${ }^{2}$

\footnotetext{
${ }^{2}$ La Convención Americana de Derechos Humanos fue suscripta en San José de Costa Rica el 22 de Noviembre de 1969 y entró el vigor el 18 de julio de 1978. En la Argentina, la ratificación se inició por medio de un proyecto de ley del Poder Ejecutivo el 18 de julio de 1978. Fue sancionada el 1 de marzo de 1984, promulgada el 19 de marzo de 1984. El instrumento de ratificación del tratado fue recibido en la Secretaria General de la Organización de los Estados Americanos el 5 de noviembre de 1984. En ese instrumento consta también la aceptación de la competencia de la
} 
Para M. A. Ekmekdjian (2002) la Reforma Constitucional de 1994 "ha sido una reforma innecesariamente exuberante, si se tiene en cuenta sus objetivos primigenios, según todos los artífices del pacto de Olivos". La verdad es que, la forclusión, es decir, el salteo de los pasos procesales en la justicia, se ejerció a nivel constitucional, ya que la Corte Suprema de Justicia convalidó tácitamente la violación al anterior art. 71 de la C.N., en la sanción de la ley 24.309 (que declaró la necesidad de la reforma), la cual fue la promulgada por el Ejecutivo Nacional. Aún cuando este autor caracteriza de francamente negativo el balance de la reforma del '94, ésta tiene ya su estirpe forcluyente en las anteriores reformas constitucionales de Argentina de 1860, 1866, 1949, 1957 y 1972, pero no siendo así en la reforma de 1898. La reforma de 1860 se efectuó sin respetar el plazo de inmutabilidad de 10 años que preveía la norma constitucional en 1853 . En la reforma de 1866, también fue impugnada en atención a la condición de formación de la mayoría parlamentaria para declarar la necesidad de la reforma. En la reforma de 1898 se modificó el número de ministros del Poder Ejecutivo y fue la única reforma constitucional que no fue objetada. La reforma de 1949 fue aprobada por la Convención Constituyente, e impugnada por parte de la doctrina con relación a la forma del cómputo de las mayorías de los 2/3 de los legisladores. "Esta reforma estuvo vigente 7 años, ya que fue dejada sin efecto por una proclama del gobierno de facto surgido en 1956, y tal derogación fue ratificada por la Convención Constituyente en 1957. La reforma de 1957 fue convocada por el gobierno de facto, situación hasta entonces inédita" (Ekmekdjian, op. cit.). La legitimidad de ésta reforma también fue impugnada, tanto por su etapa pre constituyente, como porque las actas de las sesiones no fueron aprobadas por el cuerpo. Por su parte, la reforma de 1972 fue la más cuestionadas de las reformas por no respetar la lógica de los antecedentes. En síntesis, la repetida inobservancia de los funcionarios públicos, o gobernantes estatales, a la lógica procesal constitucional a obedecer para conseguir una necesidad de reforma, habla de cierta irresponsabilidad para respetar y manejar el contrato social interno y supremo de la nación Argentina.

Tal como sostuvimos en otro trabajo, "queremos analizar las formas y las consecuencias del hecho de que habiendo aprobado, firmado y entrado en vigor tratados de derechos humanos en coyuntura con las políticas de ajustes estatales, la violencia socio-política se manifestó en demasía en el campo de lo jurídico" (Parisí, Manzi; 2012).

\section{Aspectos coyunturales a nuestro ejercicio del derecho}

En caso de que un funcionario de un gobierno prive arbitrariamente de su propiedad a un ciudadano, habrá violado la garantía contenida en el art. 17 de la Constitución, y deberá responder penalmente; y, además, el Estado podrá ser responsable internacionalmente sobre el hecho si las vías internas del derecho no investigaron, repararon y castigaron a los responsables. Por lo que no hay que

Comisión Interamericana de Derechos Humanos y de la Corte Interamericana de Derechos Humanos "por tiempo indefinido y bajo condición de estricta reciprocidad". 
confundir derechos humanos con bienes jurídicos tutelados factibles de ser violados por el Estado o por particulares. Ahora bien, se intuye que los funcionarios de turno que malversan o mal administran los recursos del Estado (simbólicos o materiales), y por suposición, se comete por omisión o comisión una violación a un derecho hacia un grupo o colectividad de la sociedad, en general no son perseguidos penal ni socialmente $y$, aún así, el Estado incurre en responsabilidad internacional. Como lo puede ser las políticas públicas de carácter represivo llevadas a cabo en materia carcelaria. El problema es investigar y procesar al/los responsable/s penal/es de un preciso derecho humano violado en un determinado momento, para con una gran colectividad social, o un individuo en particular. Encontrar a un responsable penal es tarea de cada Estado, de cada administración de justicia del gobierno de turno. Y si el Estado no lo hace, puede hacerlo un particular. Pero, si no encuentra respuestas, puede dirigirse al sistema de derecho internacional para que emita opinión o eleve sentencia sobre la responsabilidad internacional de un Estado (provincial o nacional), siguiendo y obedeciendo los tiempos formales de todo proceso legal.

Sin embargo, no ocurrió lo mismo entre los acuerdos de integración comercial al sistema financiero mundial y las reformas ejecutadas en las instituciones del Estado mediante los Planes de Ajuste Estructural. Cuestión que el estallido social de diciembre de 2001, comprobó sin rodeo alguno, que la tensión política social se remitió a: la inexistencia de sectores institucionales que articulasen las necesidades que la sociedad básicas que demandaba y de trabajadores que ejecutasen las tareas administrativas y concretas para colmarlas; y no a la falta específicamente de eficacia y eficiencia económica que la sociedad argentina presentó años anteriores, es decir, a un problema de solvencia. Comprobamos que esta tarea articulatoria entre los recursos materiales, organizativos, administrativos y de control sobre lo nacional ha sido delegada desde hace años, a una sociedad no gubernamental, sin fines de lucro, privada y financiera; que provoca -imaginariamente- en la sociedad la fábula del que se auto-organiza para auto-controlarse. Y que, simbólicamente, se reconoce y se valoriza más aún si, desde el exterior del país, se las reconoce y mantienen relaciones interinstitucionales, pero que materialmente, no se auto subvenciona ni se auto industrializa.

La situación de precariedad institucional administrativa y política de los recursos democráticos y de una planificación de la economía que excluyó a más de la mitad de la población en el goce de sus derechos económicos y sociales, más no en la participación del mercado como fuerza de trabajo y como consumidores aún cuando son tratados como desechos -durante los ' 80 , los '90 y principios de siglo; agudizó con más fuerza aún el sentimiento, mejor dicho en el imaginario colectivo y mediático, de que entre lo público y lo privado es preferible esto último por ausencia de esfuerzo mancomunado en mejorar a los primero.

Ahora bien, la gestión presidencial de Cristina Fernández de Kirchner tiene un diagnóstico de sus medidas políticas y económicas que le dan el visto bueno si se compara su gestión con la de varios gobiernos nacionales anteriores. La CEPAL en su informe de noviembre de 2011 presentado en el vecino país de Chile, dice 
que la Argentina "volvió a expandirse significativamente durante 2011, impulsada por todos los componentes de la demanda agregada, de manera similar a lo ocurrido en el año 2010, cuando creció un 9,2\%" (CEPAL, 2011) La tasa anual de desocupación se redujo a un $7,3 \%$. En el plano fiscal, el gobierno volvió a optar por el uso del propio sector público para hacer frente a las necesidades de financiamiento del Tesoro Nacional de Seguridad Social (ANSES). En enero transfirió aproximadamente 1,6\% del PBI en conceptos para atender servicios de deuda externa pública. "La tasa de inflación tendió a estabilizarse en 2011, al mantenerse por encima de la media regional, luego de haber aumentado en 2010 respecto de 2009. El ritmo de devaluación del peso, de un 0,5\% entre enero y octubre de 2011, fue similar al 2010, en tanto el índice de precios de alimentos registró una caída del 6,5\% en el mismo periodo. Por el contrario, entre enero y septiembre de 2011, a raíz de negociaciones salariales, se produjo un alza del salario medio de un 27,4\% superior al aumento del 21,2\% verificado en 2010 " (CEPAL, 2011).

La creación de la UNASUR para fortalecer la democracia en Latinoamérica, es de innegable contribución para la democracia, la economía y a los derechos humanos de la región. Además de fortalecer al Estado como regulador y activo en políticas de índole económicas en materia interna, concretizó alianzas económicas con los países del Mercosur. Esta política de fortalecimiento del Estado es tanto a nivel de administración de los recursos del país, valorización del espacio político e institucional del país, como en su dimensión judicial, ya que la actuación del sistema judicial argentino en materia de derechos humanos ha ido en aumento y en consonancia con la firma de los tratados internacionales de derechos humanos.

Hay una invocación al sistema de derecho a través de un saber hacer y un conocer, que hace de la sociedad argentina que la normación sea caracterizada por los órdenes de un discurso que enumera y clasifica, controla y codifica, narra y sentencia, tipifica y condena o absuelve, en tanto derecho humano. Más allá de una posible o evidente violación a un derecho ya establecido, la dinámica social exige, mediante un fundamentado conocimiento, disciplinarse y a la vez soberanizarse, demandando a la estructura del derecho que otorgue subjetividad a los individuos en tanto sujeto de derechos en caso de ser éstos han sido ultrajados y que dejan en estado de desvalimiento jurídico, y por ende político, a individuos. Como por ejemplo, el derecho a la identidad sexual o el derecho a la base alimentaria, fundamentado (a favor o en contra) en algunos momentos por la biología o la sociología, según se disponga.

Las subjetividades volcadas hacia la defensa de los derechos humanos condensaron también el conflicto clásico entre las normas del derecho nacional y en el derecho internacional. Para Travieso (2002) éste conflicto se subsana "aplicando los criterios relacionados con la temporalidad y la espacialidad. La última norma deroga la anterior y la regla especial prima sobre la general". Lo que significa que la especialidad lo define la particularidad del caso, su región, por así decirlo; y a partir de entonces se puede enumerar y clasificar porque hay un conocimiento previo, que es el derecho, que lo sugiere y que lo invoca. 


\section{La jurisprudencia ${ }^{3}$}

La jurisprudencia tiene valor como medio auxiliar para la determinación de las reglas de derecho y que, en caso de dificultad para hallar tratados, costumbres o principios generales del derecho, la jurisprudencia y la doctrina serán los instrumentos idóneos para determinar las fuentes. "En verdad, la mayoría de los autores coinciden en que la jurisprudencia no es fuente de derecho internacional. Sin embargo, como veremos, las resoluciones de la Corte Interamericana de Justicia de Derechos Humanos estarían asumiendo carácter de fuentes del derecho, han formado un -usus fori-, del que los tribunales no quieren salir por la amenaza siempre latente de la responsabilidad internacional. En la Argentina, por ejemplo, esa interpretación ha constituido un nuevo paradigma de aplicación por los tribunales que ha superado el paradigma anterior al dualismo Derecho Internacional-Derecho Interno. El margen de penumbra que detentan las normas de la Convención Interamericana de Derechos Humanos, se clarifica con la jurisprudencia" (Travieso, 1998). Básicamente, la función que se desprende de la estructura del derecho internacional sería que los órganos internacionales encargados de dictaminar fallos, tienen en cuenta cuál es el derecho de determinado tratado internacional que se considera lesionado en tal o cual jurisdicción, pero no se interrogan acerca de cuál es el derecho violado perteneciente a la Constitución interior o de ese Estado. "Sin duda, la jurisprudencia de la Corte Interamericana de Derechos Humanos, es la voz de los silencios de la Convención Interamericana de Derechos Humanos" (Travieso, op. cit.).

De todas maneras, "la cita de precedentes es habitual en la práctica de los tribunales nacionales e internacionales, especialmente en los fallos propios de cada órgano judicial constituyendo generalmente elementos de coherencia dentro de una serie. Un fallo es la consecuencia directa de otro u otros y cada fallo $u$ opinión consultiva se basa en anteriores fallos, opiniones, consultivas o dictámenes. En todo sistema de derechos es imprescindible que haya un margen de predictibilidad" (Travieso, op. cit.). En consecuencia, sería posible afirmar que el sistema de derecho busca la coherencia en tanto interpreta leyes y aplica fallos. Se considera lógico que un tribunal siga la línea interpretativa que ha utilizado anteriormente, ya que promueve la intención de previsibilidad en el sistema del derecho, teniendo cada ley fundamental su lugar de particular sujeción que sostiene a las demás. Así se esclarecen los canales de la interpretación de las normas en los diversos casos, y además se podría predecir acertadamente lo que un tribunal decidirá en casos similares.

\section{Los casos}

El fallo del caso Ekmekdjian c/ Sofovich en 1992 fue el que a partir de entonces los tribunales locales comienzan a tener en cuenta los elementos de las opiniones,

\footnotetext{
${ }^{3}$ Jurisprudencia es el derecho judicial, cuando de él (en cuanta fuente del derecho constitucional) surge y entra en éste la norma no escrita de reconocimiento de los derechos. Es decir, mediante sentencia, establece norma a obedecer. Es la creación de derecho por los jueces.
} 
consultivas y fallos de las Corte Interamericana de Derechos Humanos (CIDH). También ya en 1983, en el caso Cabrera Washington c/ Salto Grande hubo referencia a la competencia de la Corte Suprema de la Nación de la responsabilidad internacional que puede incurrir un Estado en sus decisiones, denominándose así "leading case" ${ }^{4}$. La CIDH "después de más de diez opiniones consultivas, se presentó un caso contencioso, para el que se aceptó competencia al efecto. El fallo contencioso tenía los cimientos bien construidos, pues al llegar a la cúpula, la construcción estaba suficientemente preparada con opiniones consultivas estables. Teniendo en cuenta las decisiones judiciales de los tribunales internos, parecería que la jurisprudencia de la Corte Interamericana, actúa como elemento estabilizante y homogeneizante de las resoluciones judiciales" (Travieso, op. cit.).

A partir de entonces la Corte Interamericana de Justicia ha dictaminado fallos en numerosos casos que conciernen a violaciones a los derechos humanos en toda América Latina, efectivizando el valor real de la ratificación de los tratados internacionales de derechos humanos y obligando a cada Estado parte a tomar medidas directas y concretas para resarcir los derechos violados.

Esto, al decir de Bidart Campos (1989), es una impronta más para que los derechos humanos comiencen a tener vigencia sociológica y no sólo normativa. "La gama de técnicas hasta hoy usadas en las jurisdicciones supra estatales existentes es diversa: puede ser el acopio de información sobre la situación de los derechos en un Estado, puede ser la emanación de recomendaciones o informes, puede ser los mecanismos de conciliación, y puede ser una decisión de tipo judicial, y hasta sancionador".

\section{Jurisprudencia: Libertad de expresión}

El fallo Ekmekdjián c/ Sofovich de 1992, "tiene una base sobre la cual se ha construido una verdadera doctrina en materia de libertad de prensa, de expresión, de pensamiento y derecho de información y respuesta" (Travieso, 1998). Dentro del campo del derecho a la libre expresión, antes, en 1984, la Corte Suprema de Justicia dictó el fallo del caso "Indalia Ponzetti de Balbín c. Editorial Atlántida". Para Travieso, "desde este fallo en adelante, la jurisprudencia con mayor o menor decisión no dudó en aplicar los principios del Derechos Internacional" (Travieso, op. Cit.). Otro caso sobre el tema fue "Campillay Julio César c/ La Razón, Crónica y Diario Popular" en 1986. Hubo otro que fue en 1987 con el fallo "Costa Héctor Rubén c/ Municipalidad de la ciudad de Buenos Aires y Otros s/ Daños y perjuicios", y también el fallo "Servini de Cubría M. R. c/ Mauricio Borensztein s/ Amparo" en 1992. Por parte de la Comisión Interamericana, uno de los primeros casos de su aplicación, fue el caso "Sarotto Aníbal José c/ Panadería Argentina s/ Amparo" en 1986. En 1987 se destaca el caso "Costa Héctor R. c/ Municipalidad de la Ciudad de Buenos Aires" y el caso "Sánchez Abelanda Raúl c/ Ediciones La Urraca" fallados por la Corte Suprema. Y también en 1989 la Corte Suprema emitió su fallo en el caso "Verbitsky, Horacio y otros."

\footnotetext{
4 "Leading case": caso líder, o caso base, a partir del cual comienza la jurisprudencia.
} 
Todos estos casos fueron oportunidades para que la justicia argentina fuese construyendo su edificio jurídico a través de la ejecución de normas establecidas, es decir, para que procediera a delimitar los conceptos de libertad de prensa, ya que el problema básico es que el principio del derecho a la libre expresión e información no es absoluto y el régimen republicano exige no facilitar la impunidad de prensa. El ejercicio del derecho a informar debe hallarse en necesaria armonía con los restantes derechos constitucionales entre los que se encuentra la integridad moral y el honor de las personas: "El tema quizás más relevante en cuanto al derecho de expresión es el que se refiere a la posibilidad de ulterior responsabilidad. El principio clave es que no procede la censura previa, sin que ello obste la responsabilidad ulterior. La Corte Interamericana ha establecido los requisitos para el establecimiento de la responsabilidad: a) La existencia de causales de responsabilidad previamente establecidas, b) La definición expresa y taxativa de esas causales por la ley, c) La legitimidad de los fines perseguidos al establecerlas, $y d$ d) Que esas causales de responsabilidad sean necesarias para asegurar los mencionados fines" (Travieso, 1998). Por lo que significa que la libertad de prensa no debe ser absoluta, a la vez que se prohíbe la censura previa. Así se resolvió este enfrentamiento entre dos derechos, entre dos fuerzas bajo la epistemología del soberano y de la disciplina. Controlar y legislar, enumerar y tipificar, procesar y sentenciar. Con respecto a este derecho, no hay prohibición, y a la vez hay sentencia. Sin embargo, "sin la existencia del derecho de réplica con el contenido amplio que pretendemos asignarle, la libertad de prensa para todos es un mito, un mero catálogo de ilusiones, una simple afirmación dogmática" (Ekmekdian, 2002). Fue justamente el caso "Ekmekdjian c/Sofovich" a partir del cual la Corte Suprema de Justicia consagró expresamente el derecho a réplica como un efectivo ejercicio de la libertad de prensa, ya que aquel protege el derecho al honor, a la intimidad y a las convicciones fundamentales de las personas (religión, profesión, nacionalidad).

Ahora bien, en esta pugna por posibles e inevitables superposiciones de derechos fundamentales, como lo ejemplifican estos casos entre el derecho a la libre expresión y el derecho a la integridad moral, Travieso le da importancia a la tensión entre información veraz y censura. En lo que respecta a este tema, dice que: "en las sociedades contemporáneas se está empleando la institución del Ombudsman que representa un camino alternativo para mediar, solucionar $y$ actuar a título preventivo. La única manera de no limitar o censurar a los medios de expresión podría consistir en el establecimiento de un ombudsman para los medios de expresión, designado y promovido por el Parlamento, responsable ante éste, y auxiliado por un consejo asesor de Organizaciones No Gubernamentales, nacionales e internacionales de reconocido prestigio" (Travieso, 1998.). La importancia para nuestro análisis no es sólo la conclusión de que en cuanto a la libertad de expresión, las relaciones de fuerza tuvieron su batalla; sino también la posibilidad, todavía no obligatoria, de una figura civil que asesore la libertad de expresión. Comprobamos que las ONGs tienen un lugar para cumplir una función en relación con los derechos humanos, sin sustituir a la Justicia. La sociedad civil que se auto-organiza también comienza a auto-controlarse y a clasificarse, enumerarse y juzgarse. $Y$ no sólo con respecto a este derecho en particular, sino 
también como los siguientes a investigar. Este camino de denuncia ya fue marcado por los organismos de derechos humanos nacidos a fines de los setenta.

Entonces a partir de la Reforma Constitucional de 1994, la relación del derecho interno con el derecho internacional cambió. Para 1995 la Corte Suprema afirmó el principio internacional de libertad de expresión e hizo lugar al habeas corpus presentado a favor del ciudadano Pablo Calvetti (rechazado por la Corte Suprema de Justicia de Tucumán), quien hubiera sido arrestado por publicar una carta con comentarios sobre la actuación de un legislador. En 1995 estuvo la causa "Kogan, Nocolás s/ Calumnias e injurias". En 1996 se falló en el caso "Morales Solá Joaquín s/ injurias", y en "Gesualdi, Dora c/ Cooperativa Periodistas Independientes Limitada y otros s/ cumplimiento ley 23.073". En 1997, la misma Corte dictó su fallo en el caso "Emisiones Platenses S. A. s/ Acción de Amparo". Todos estos encuadrados dentro de la libertad de expresión que citan a las fuentes de derecho internacional, aunque si bien las decisiones finales de la Corte no representan la mayoría absoluta a favor de la misma. Recién en el 2009 se eliminó la figura delictiva "calumnias e injurias", que fue promulgada en los primeros años del gobierno de Menem. De esta manera también se construyó el edificio jurídico.

\section{Las Garantías}

También es a partir de esta Reforma Constitucional que las figuras de habeas corpus, amparo y habeas data se les confiere rango constitucional en el art. 43. Son recursos judiciales efectivos a todas las personas que se hallen bajo la jurisdicción del país que haya ratificado los pactos internacionales de derechos humanos. "La palabra garantía debe entenderse en el sentido en que se halla en el art. 27.2 de la CIDH, en el título correspondiente a suspensión de garantías, interpretación y aplicación. ${ }^{5}$ La Corte Interamericana de Derechos Humanos ha expresado que las garantías sirven para proteger, asegurar o hacer valer la titularidad o el ejercicio de un derecho revistiendo el carácter de Derechos Humanos fundamentales inderogables" (Travieso, 1998). Vale decir que las garantías son los medios idóneos para que los derechos y libertades se hagan efectivos. Algunas garantías previstas en el art. 18 de la C.N. son genéricas, es decir, que sirven de protección para todos los derechos. La tendencia es ir ampliando el ámbito de protección especial a otros derechos. La acción de amparo es la vía reservada para delicadas y extremas situaciones en las que peligra la salvaguarda de derechos fundamentales como la vida, la salud, y la satisfacción de necesidades asistenciales básicas. (Cámara Federal de Corrientes, 2000/11/03.- Lavoletta, Justa J. y otros c/ PAMI). En realidad, el amparo surgió en 1957-1958 por fuente de derecho judicial emanado de la Corte Suprema, cuando aún no existía norma escrita que lo contuviera (Bidart Campos, 1989).

\footnotetext{
${ }^{5}$ Art. 27.2: La disposición procedente no autoriza la suspensión de los derechos determinados en los siguientes artículos ni en las garantías judiciales indispensables para la protección de tales derechos".
} 
El habeas corpus ha sido previsto para corregir el agravamiento de las condiciones ilegítimas del modo y condiciones en que se cumple la detención, es decir, para evitar mortificaciones que excedan las precauciones exigidas por la seguridad, sin prejuicio de las facultades propias del juez del proceso si lo hubiere (Corte Suprema, 1999/11/01.- G., J. C.). Se trata de un mecanismo protector aplicable para cualquier tipo de privación de libertad, sin distinción alguna sobre la naturaleza y que procede para los demorados, arrestados, detenidos preventivamente en el proceso penal y condenados a penas privativas de libertad; convirtiéndose en un medio legal adicional, rápido y eficaz para resguardar el trato digno en prisión. Hasta antes de la reforma de 1994, la jurisprudencia y la doctrina, hacían derivar el habeas corpus directamente del art. 18 de la C.N.

Otros casos de jurisprudencia con respecto a las garantías procesales se dieron mucho antes, en 1984. Uno de ellos fue "Cuccaresi Ricardo D. s/Excarcelación" cuya defensa solicitó la aplicación de la CIDH y de la ley 23.054 que consagró el derecho a toda persona a ser juzgada en un plazo razonable o ser puesta en libertad. No se dio lugar a la operatividad de la CIDH, entre otras cosas, porque el imputado ya registraba condenas anteriores. También en el mismo año se solicitó la excarcelación en "Molinari J. A.", la cual fue rechazada porque la excarcelación no encuadraba en las normas vigentes y por los antecedentes personales del procesado. En 1987 la Corte Suprema nuevamente tuvo la oportunidad de fallar sobre el mismo planteo en la causa "Firmenich M. s/ Incidente de excarcelación". "Entró en el análisis del art. 7.5 de la CIDH, y consideró que el juicio sobre la prolongación de la privación de la libertad cautelar debe estar relacionada con las circunstancias concretas de cada caso. La Suprema Corte se remite a la interpretación de la jurisprudencia de la Corte Europea de Derechos Humanos en el caso Neumeister y Reingeisen por interpretación del art. 5.3 de la Convención Europea de Derechos Humanos. Siguiendo la doctrina de esos fallos, la Corte Suprema consideró que hay una relación entre las características del delito que se imputa, las condiciones del procesado y la pena con que se reprime el hecho" (Travieso, 1998). En el fallo Firmenich, la Corte no hizo lugar a lo peticionado. Sin embargo, el "leading case" sobre esta materia, a partir del cual se concluyeron las diferentes interpretaciones sobre el plazo razonable de detención entre los tribunales federales y provinciales fue "Arana Juan Carlos s/ excarcelación", en 1995. En sus considerandos se cita a la Convención Americana de los Derechos Humanos.

Para el 2001, el CELS interpuso ante el Tribunal de Casación Penal de la Provincia de Buenos Aires una acción de habeas corpus para todos los detenidos alojados en dependencias penitenciarias de la provincia, debido a la superpoblación existente, llegando a 6.364 alojados para una capacidad de 3.178. Este tribunal se declaró incompetente para tratar la acción y consideró que su aptitud es limitada y no prorrogable. En esta causa, ocho organismos nacionales e internacionales presentaron memoriales amici curiae. El Ministerio de Justicia de la provincia proveyó un informe en que declaraba que la población carcelaria subió de 23.264 en el 2001, a 30.414 en el 2004; reconoció la existencia del incremento de juicios en espera y el abuso de la utilización de prisión preventiva. Recién en el 2005 la Corte Suprema de Justicia de la Nación (CELS, 2005a) emitió su 
sentencia haciendo lugar a la acción de hábeas corpus, y consideró que la situación presentada constituye una violación a las normas constitucionales y normas internacionales. Pero, en realidad el primer caso correctivo colectivo que se refiere a presos y fue resuelto por la Corte fue "Mignone", en 1999. El organismo no gubernamental demandó por inconstitucional la norma del Código Electoral que prohibía votar a presos. La Corte acogió el amparo colectivo y dispuso que el Estado argentino dispusiese de los medios necesarios para hacer efectivo el voto a cerca de 5.000 penitenciarios.

En setiembre del 2003 la Corte Interamericana de Derechos Humanos condenó al Estado argentino a remunerar económicamente y a realizar medidas correspondientes para adecuar el ordenamiento jurídico interno a las normas internacionales, por la muerte de Walter Bulacio, un menor de edad que en 1991 fue detenido junto a otras 73 personas en un recital de música del grupo rockero Redonditos de Ricota. Así, se establecieron requisitos que deben cumplirse para que una detención sea legítima y se fijaron condiciones especiales para los casos de privación de libertad a menores de edad. Como estamos analizando, aún no se han verificado cambios sustanciales en la materia y se comprueba la continuidad de las prácticas de detención.

"Como se observa, en el edificio del derecho nacional y su relación con el internacional, poco a poco se afianzó una relación más recíproca para realizar sus interpretaciones de normas" (Parisí, Manzi; 2012). Al decir de Travieso (2002), se entiende como retroalimentación a esta relación recíproca que se produce al incorporarse criterios de interpretación internacionales a los fallos nacionales.

\section{Doble instancia procesal}

Como continúa Travieso (1998) en sus análisis de fallos que sientan jurisprudencia en derechos humanos, el caso "Giroldi Horacio s/ recurso de casación" de 1995, "ha reiterado la relación de pauta interpretativa de la jurisprudencia de la Corte interamericana de Derechos humanos para la Corte Suprema de Justicia. La relevancia de esa consideración significa que la Corte Argentina deba fundamentar expresamente el caso de apartamiento de los precedentes de la Corte Interamericana. Esa expresión, en conjunto con otros fallos, constituyen la expresión más concluyente de la supranacionalidad que se está verificando en el orden jurídico argentino". Sobre este caso se asientan los casos "Martins, Raúl Luis s/ defraudación" en 1996 y "Arce, Jorge D." en 1997. Estos casos no van de suyo ya que tratan el derecho a recurrir a una instancia superior, es decir, incumbe a la garantía de la doble instancia penal. Por su parte, la CIDH llegó a abrir nueve casos sobre este tema, la mayoría pertenecientes a Costa Rica, pero sólo se pronunció sobre el primero de ellos, e instó a Costa Rica que dispusiera medidas adecuadas para resolver estos casos. Hasta entonces, la CIDH se abstuvo de opinar antes de que este país tuviera la obligación y la oportunidad de regirse él mismo por los tratados internacionales, evitando así la distorsión del sistema de la Convención. 


\section{Responsabilidad internacional}

Con respecto a otros temas, que vinculan la obligación de regirse por estándares internacionales de derechos humanos, hay uno que urge atender por la particularidad que la realidad en argentina muestra. La situación de las cárceles argentinas muestra lo lejos que se está de cumplir con las normas de los Pactos Internacionales que establecen, entre otras cosas que: nadie será sometido a torturas ni penas crueles, inhumanas o degradantes; y que toda persona privada de libertad será tratada humanamente, teniendo derecho a la integridad física, psíquica y moral. La superpoblación carcelaria, las condiciones de deterioro y precaria de las cárceles, la violencia encubierta y silenciada entre presos y también de los carceleros, más una clase criminalizada por pobre, configuran un caldo de cultivo para que el Estado incurra en irresponsabilidad en varias de sus obligaciones. Además de las recién citadas, es cotidiano que en estas condiciones no se cumpla el derecho a la salud (las consecuencias severas de los casos de presos con sida que no reciben medicación); y el derecho a la educación. El sistema carcelario da cuenta de que es una institución estratégica de dominación que administra excluidos más que la re-socialización que deberían hacer y asegurar su reingreso a la vida cotidiana. Por ejemplo, en 1994 la causa "Internas U. P. VIII (Los Hornos) s/ acción de amparo", el juzgado en lo Criminal y Correccional de La Plata falló a favor de las internas en cuanto son portadoras del virus HIV porque fueron las condiciones de privación de libertad, más las sanciones disciplinarias y la carencia de atención médica lo que produjeron un pronunciado deterioro psíquico y físico en todas las internas infectadas. En sus considerandos citan a la Carta Internacional de los Derechos Humanos de 1948 y el Pacto de Derechos Civiles y Políticos de 1966. En 1995 "Dessy, Gustavo G." interpuso un habeas corpus por haber sido agravado en sus condiciones de detención al violar su correspondencia y afectar sus derechos a la intimidad y privacidad, el cual fue denegado. ${ }^{6}$

Por su parte, la Asamblea General de las Naciones Unidas adoptó el 18 de diciembre de 2002 el Protocolo Facultativo de la Convención contra la Tortura y otros Tratos o Penas Crueles, Inhumanas o Degradantes. La ratificación de este Protocolo por parte de la Argentina fue en el 2004, y se aprobó mediante la sanción de la ley 25.932. El objetivo es prevenir malos tratos y torturas mediante visitas regulares "in situ" a los lugares de detención por parte de organismos independientes de carácter nacional e internacional. Éste Protocolo impone deberes a los Estados firmantes para reforzar los mecanismos de control sobre las condiciones carcelarias. ${ }^{7}$ En el 2001 y el 2002 se hicieron las presentaciones

\footnotetext{
${ }^{6}$ El Protocolo Facultativo de la Convención contra la Tortura y Otros Tratos o Penas Crueles, Inhumanos o Degradantes se aprobó en nuestro país, mediante la sanción de la ley 25.932. El objetivo de este instrumento es prevenir la tortura y los malos tratos mediante un sistema de visitas regulares a lugares de detención llevadas a cabo por órganos independientes de carácter internacional y nacional.

7 Según información suministrada por la Procuración General de la Nación, entre enero de 2000 y junio de 2004 se iniciaron más de 4.000 investigaciones por los delitos de apremios ilegales y torturas en el ámbito de la Justicia Nacional Ordinaria de la Prov. De Bs. As. y de la Justicia Federal de todo el país. Se dictaron sólo catorce sentencias condenatorias, todas por delitos de
} 
anuales por parte del CELS ante la Oficina del Alto Comisionado para los DDHH de la ONU; en el 2003 presentó un informe al secretario ejecutivo de la $\mathrm{CIDH}$; en el 2004 ante el Comité Contra la Tortura de la ONU. También el 2004, pero esta vez abogados del Movimiento Ecuménico por los DDHH presentaron medidas cautelares ante la Comisión IDH por la excesiva cantidad de muertes dudosas en los servicios penitenciarios de Mendoza. El Banco de datos de Casos de Tortura, creado en el 2000 , registró 2.551 casos de torturas y malos tratos para el periodo entre marzo del 2000 y agosto del 2004; y 2.914 denuncias entre setiembre de 2000 y junio de 2004 en perjuicio de Menores Tutelados (CELS; 2005a). Es así que, la presentación de hábeas corpus individuales y colectivos, constituye la única herramienta de los defensores públicos para dar visitas regulares y no anunciadas a los establecimientos de detención para monitorear las condiciones de detención. Y también como modo de acceder el contacto con un juez, ya que prevé la realización de una audiencia judicial obligatoria.

\section{Derecho a la salud}

Con relación al ejercicio del derecho a la salud y el suministro de medicamentos en el sistema carcelario, pero ya en el ámbito administrativo, se encuentran los fallos "S.N. c/ Policía Federal" de 1996. En 1999 la Corte Suprema dejó sin efecto la sentencia del Juzgado $\mathrm{N}^{\circ} 1$ de Mendoza e hizo lugar al recurso de habeas corpus presentado en la causa "G., J. C.". En los considerandos se encuentran citados varios tratados internacionales en los que amparan la dignidad humana de una persona privada de su libertad. El caso "Roberto Felicetti y otros - La Tablada" fallado por la Cámara de Casación Penal en noviembre y en diciembre del 2000 por la Corte Suprema, desestimó el recurso de revisión articulado por los condenados por el copamiento al cuartel de La Tablada. ${ }^{8}$ Los recurrentes presentaron el recurso para que se revisasen las condenas que les fue impuesta en 1989 apelando a la doble instancia. Para Palacio de Caeiro (2001), la doctrina de la Corte Suprema sentada en este caso ha "reafirmado la tendencia monista que se ha impuesto en el sistema jurídico argentino a partir de la reforma del 94, ha reiterado que la doble instancia en el proceso penal, es una exigencia nacida del derecho de los tratados internacionales, ratificado la pertinencia de las cláusulas de los tratados internacionales al derecho federal, establecido el valor no vinculante $y$ obligatorio que tienen los criterios interpretativos y recomendaciones de la CIDH". Está presente el carácter monista que este comentario particular del fallo le otorga a la tendencia de la influencia del derecho internacional. Pero lo más importante a rescatar, para este trabajo, es la tendencia que existe, al menos en esta esfera de la vida social, a judicializar temas que tendrían que ser resueltos administrativamente.

A principios de 1996, y en los dos siguientes años, las ONGs Asociación Benghalensis, Fundación Descída, FEIM, Asociación Civil Intilla, Fundación

apremios ilegales, y el 1,6\% fue calificada como tortura. (CELS, 2005)

${ }^{8}$ En ambos casos se desestimó el recurso articulado por los condenados que buscó argumentos para lograr la revisión de las penas impuestas en el año 1989 por el copamiento al cuartel de La Tablada. 
R.E.D., Fundación CEDOSEX, Fundación Argentina pro Ayuda al niño con Sida y Asociación Civil S.I.G.L.A., promovieron una acción de amparo contra el Estado Nacional y el Ministerio de Salud y Acción Social. Esto, con el fin de que cumpliere con sus obligaciones de asistencia, tratamiento y rehabilitación y administración de medicamentos a las personas que padecen deterioros a causa del virus HIV, en todos los hospitales y efectores sanitarios del país. Este caso es paradigmático según nuestro punto de vista, ya que en él confluyen diversos sectores sociales y dimensiones que hemos venido desarrollando a lo largo del trabajo. La Jueza Federal Rodríguez Vidal, hizo lugar a la medida cautelar peticionada en este caso, en consecuencia: "hágase saber al Ministerio de Salud y Acción Social de la Nación que por intermedio de la Secretaría de Recursos y Programas de Salud de Lucha contra Retrovirus Humanos, deberá adquirir y entregar a cada uno de los efectos sanitarios del país, los reactivos y medicamentos incluidos en el vademécum Básico aprobado en 1994" (Travieso, 1998).

Se percibe la función complementaria y no administrativa del sistema judicial a las políticas administrativas, promoviendo y estableciendo obligación legal al Estado. Pero no establece responsabilidades de funcionarios de haber hecho incurrir al Estado en irresponsabilidad internacional. A la vez, en la efectividad y necesidad del control y denuncia de las violaciones a derechos se comprueba que es la sociedad civil, reconocida simbólica y materialmente, la que porta la legitimidad y la fuerza de ejercer los medios idóneos del sistema del derecho. Por lo que también significa que, sin la movilización de este sector, los crímenes o delitos referidos a derechos humanos difícilmente sean denunciados si los demás ciudadanos no tienen los recursos (educativos, materiales y con fuerza política) necesarios para saber y poder actuar. Entre las disciplinas y la soberanía se juega el ejercicio del poder. Entre el disciplinamiento del mercado excluyente y el derecho a demandar, las fuerzas de los distintos sectores sociales, luchan dentro del sistema judicial.

Además de la falta de recursos del Estado y de la responsabilidad de los funcionarios de administrar a los mismos, la situación se ha visto opacada por la presencia de los niveles de precariedad y violencia en las cárceles, por el colapso del sistema de salud, por la ausencia de instituciones contenedoras de lo social como lo es la escuela y las municipalidades. Es decir, básicamente es el Estado el que está obligado a cumplir con los estándares, pero los funcionarios del Estado no son penalizados por malversación de los recursos administrativos, en caso que el detrimento del goce de los derechos sea denunciado, comprobado y sentenciado. Pareciera que la judicialización de los derechos humanos no permite visualizar las causas de la ineficiente administración de los recursos y definir: si es por faltas cometidas por funcionarios públicos, a los cuales les cabría una responsabilidad; o por la escasez de recursos y de funcionarios públicos que lleven a cabo los medios idóneos y las medidas operativas eficaces.

\section{Otros casos de jurisprudencia}

Durante 1999 una mujer de 40 años, 10 hijos y situación económica mala, 
promovió una acción de amparo contra el Ministerio de la Salud Pública de Buenos Aires, ya que éste tenía la intención de proceder a aplicarle una ligadura de trompas. ${ }^{9}$ En este caso, fallado en febrero de 2001, "ante la controversia entre la aplicación de normas de carácter y/o provincial, el juez procede correctamente y aplica normas internacionales" (Travieso, 2002). Como dijimos anteriormente, el principio de la espacialidad también rige para la aplicación de los tratados internacionales y en consecuencia hay que analizar entre los jerarquizados y determinar cuál es el más aplicable. La Cámara declaró la deserción del recurso apelado y confirmó la sentencia de primera instancia de proceder con los medios pertinentes para efectuar la ligadura de trompas.

También en el 2001, el defensor de menores pidió autorización judicial para que permitiera donar material anatómico, a un menor afectado por atresia de las vías biliares, que no tenía parentesco requerido por la ley 24.193 que dictamina la obligación de ser pariente de un menor para realizar trasplante de órgano. El juez de primera instancia hizo lugar a la petición y aplicó el principio Pro Homine y protegió el derecho a la vida. Pero, para Travieso (2002): "se perdió la oportunidad dados los hechos del caso, de permitir la auto ejecutoriedad al derecho internacional de los derechos humanos". Esto es, haber citado a la Convención Internacional sobre los Derechos del Niño, cuestión que la magistrada no hizo.

En relación con los derechos sociales, o con el disciplinamiento del mercado excluyente, en 1999, un grupo de beneficiarios con el asesoramiento del CELS, denunció ante la Oficina Subregional del Banco Mundial en Buenos Aires, que hubo un recorte presupuestario aplicado al programa Pro-huerta y que, por lo tanto, constituyó un incumplimiento de la cláusula social mantenida con el acuerdo del organismo de crédito. Estas cláusulas fueron incorporadas durante los años '90 por los organismos de créditos como obligaciones de los Estados a prestar para el desembolso de créditos. "En 1998 el presupuesto del Programa Social Alimentario Pro-huerta ${ }^{10}$ había sido de 11,2 millones de pesos que permitió atender a una población de 2.744 .0956 personas. Inesperadamente la Ley de Presupuesto para el año siguiente destinaba al Pro-huerta 4 millones de pesos, es decir, el 32\% del total presupuestado originalmente por la propia Secretaria de Acción Social" (CELS, 2008). Obviamente, primero hubo reclamos sin éxitos por vías internas mediante la demanda, por el derecho alimentario. También hubo inacción por parte de la gerencia local del BM, por lo que se denunció ante el Panel de Inspección, organismo cuasi independiente del B.M., que controla regionalmente que las políticas se lleven a cabo. A partir de la denuncia del Panel, conjuntamente con la solicitud al BM de retención de desembolsos al Estado argentino, el gobierno garantizó los 4,5 millones hacia este programa.

Llama la atención que durante el 2011 han sucedido algunos sucesos que, por poca relevancia que han ocupado en los medios de comunicación, no por esto son menos esenciales si de discutir y analizar los derechos humanos se trata. El

\footnotetext{
${ }^{9}$ Teniendo como jurisprudencia vinculada casos en Mar del Plata en 1996, Trenque Launquen en 1997, Río Cuarto en 1994 y General Roca en el 2000.

${ }^{10}$ Su prestación consiste en la distribución gratuita de semillas y capacitación para trabajar la tierra y adecuar la dieta a los alimentos que se obtienen de la huerta.
} 
primero, la situación de integrantes del pueblo Mapuche, quienes en el 2002 comenzaron a tener conflicto legal con la multinacional Benetton. Fueron desalojados violentamente en ese año, procesados y absueltos. El tribunal decidió que las 535 hectáreas le pertenecían a la empresa. Durante el 2004 fueron invitados por Luciano Benetton a Roma para retomar un diálogo. El empresario decidió donar 2.500 hectáreas al Estado argentino para que éste les restituyera las tierras. Los Mapuches consideraron que no se puede donar lo que es no es de uno. Durante el 2007 la comunidad mapuche decidió volver a su territorio de origen, ubicado en la provincia de Chubut. El fallo del juez Omar Magallanes ordenó, en marzo de 2011, el desalojo de la comunidad mapuche de sus tierras favoreciendo a la multinacional Benetton. A pesar de que se haya sancionado la ley 26.160 de Emergencia de Propiedad Comunitaria durante el 2006 y prorrogada hasta el 2013, se considera que el juez en este caso ha actuado aplicando el derecho civil y no el derecho internacional de los pueblos originarios. La justicia de Neuquén, por su parte y para la misma fecha, falló en contra de la empresa petrolera Piedra de Águila que pretendía impedir los reclamos de la comunidad mapuche Wentru Trawel Leufu afectados por la invasión a su territorio ancestral. La sentencia que sienta jurisprudencia afirma que se transgredió la ley al no haber informado y obtenido el visto bueno de la comunidad para explotar los recursos naturales de la comunidad, remarcando la obligatoriedad de respetar legislación nacional e internacional que protege los derechos de los indígenas. El conflicto se generó en 2007 cuando el gobierno neuquino otorgó la concesión de 3.800 hectáreas de tierra para exploración y extracción petrolera. La empresa decidió ingresar por la fuerza a tierras indígenas ya que éstos le negaron firmemente la posibilidad de extraer petróleo. Durante todo el 2008 esta comunidad sufrió ataques a sus miembros humanos y animales, se les incendiaron viviendas y fueron forzados a abandonar sus tierras; todo esto también mediante una campaña mediática en responsabilizarlos por impedir inversiones extranjeras y, por lo tanto, futuro trabajo para la provincia. La empresa también presentó un recurso de amparo en donde solicitó que se le impidiera a la comunidad mapuche realizar acciones que pudiesen entorpecer la extracción de los hidrocarburos. Por suerte, el juzgado $\mathrm{n}^{\circ} 2$ de Cutral-Có negó esta solicitud de amparo y priorizó el derecho indígena. Remarca el fallo la acción inconsulta de empresas y de gobiernos viola la $\mathrm{C}$. N., la de Neuquén y los tratados internacionales sobre los derechos de indígenas y el Convenio 169 de la OIT.

El segundo suceso se refiere a las denuncias de trabajo esclavo por parte de la AFIP en las provincias de Capital Federal, Catamarca, Neuquén, Santa Fe, Mendoza y La Rioja. El aspirante a la gobernación de la provincia de Salta, el diputado Alfredo Olmedo, ha sido indagado por la justicia en el marco de la investigación por causa de "reducción de servidumbre" a 400 empleados rurales de la finca AHO ubicada en la provincia de La Rioja. La finca fue clausurada porque los obreros vivían hacinados en carpas plásticas, dormían sobre tarimas, contaban son un solo inodoro para todos y se les proporcionaba alimento en mal estado. En Catamarca, 296 aceituneros trabajaban en condiciones infrahumanas, contratados por empresas que reciben distintos tipos de subsidios por parte del Estado. Los empleados manifestaron que provenían de las provincias de 
Tucumán, Salta y Jujuy; que dormían en cuchetas sólo con colchón, sin agua potable y con productos químicos, ya que era la que se utilizaba para el riego. No poseían ni indumentaria de seguridad adecuada de trabajo, ni horarios fijos, ni atención médica mínima y ni seguro obligatorio. En la Ciudad de Buenos Aires, la oficina de la AFIP en conjunto con la Dirección nacional de Migraciones y el Ministerio de Trabajo de la Nación, inspeccionó tres talleres textiles donde se cumplían 12 horas de trabajo, sin descansos, y en donde el 90\% de los empleados no estaba registrado. Bajo estas condiciones, el secretario de Derechos Humanos, Eduardo Luis Duhalde, anunció que el organismo será querellante en las causas judiciales por trabajo esclavo o trata de personas en empresas agropecuarias. Los casos de La Pampa y Mendoza se refieren a las explotaciones de trabajadores por parte de la empresa Nidera, Southom Seed Production, Status Ager, entre otras. En los campos de Santiago del Estero los peones explotados eran contratados por la compañía de recursos humanos de Adecco.

\section{La información en el juego de las relaciones de poder}

Una nueva garantía ha debido introducirse, motivado por el desarrollo de la tecnología y las consecuencias sobre el desarrollo de la información, por primera vez en la Constitución Nacional a partir de la Reforma del 94. Se trata del "habeas data" establecido en el art. 43, par. 3 de la C.N.: "Aunque el habeas data empezó a ser invocado y trabajado por los tribunales inferiores (con mucha proyección en el campo civil y comercial), faltaba ese pronunciamiento definitivo, esa palabra rectora, que sólo confiere a un instituto jurídico la voz de la Corte Suprema. En materia de habeas data, esa decisión es "Urteaga" (sentencia del 15 de octubre de 1998)" (Carnota, 2002).

El habeas data es una garantía de un derecho individual, personalísimo que solo puede ser ejercido por el titular del derecho a interponer la acción, en defensa de aspectos de su personalidad, vinculados con su intimidad, que no puede encontrarse a disposición del público o ser utilizados sin derecho. No es una situación como el habeas corpus, cuya función es la defensa de la libertad física, sino una garantía a controlar los propios datos almacenados en registros públicos, o privados, destinados a proveer informes. Y se contempla la posibilidad de exigir supresión, rectificación, confidencialidad o actualización de los datos, sean verdaderos o falsos. No se afecta el secreto de las fuentes de información periodística, ya que como establece el art. 43, con el ejercicio de esta garantía "no podrá afectarse el secreto de las fuentes de información periodística". Este caso, "Urteaga, Facundo Raúl c/ Estado Nacional, Estado Mayor Conjunto de las FFAA, s/ amparo ley 16.986" de 1998, es considerado el leading case. Todos los jueces del tribunal supremo "quisieron dar solución efectiva al pleito, cuyo núcleo central era el drama existencial de una persona que buscaba información de su hermano desaparecido, sin anclarse en óbices u ápices ritualistas o frustratorios" (Carnota, op. Cit.). Existen tres casos que reúnen las características de los criterios descritos anteriormente que datan del año 1994, 1995 y 1997 para abordar el tema de habeas data. Pero en el 2000 fue reafirmada la operatividad de esta garantía mediante el fallo de la Corte Suprema, "Ganora", en el cual "en el considerando 13 
del voto mayoritario concluye que el habeas data incluso es procedente en principio contra los bancos de datos existentes en organismos y fuerzas de seguridad, las relaciones exteriores o una investigación criminal" (Carnota, op. Cit.). De esta manera, con la ayuda de la informática y la masificación de la misma, la necesidad social ha creado la ley, la que se refiere al cuidado de diseminación de determinados conocimientos considerados como personalísimos, y también la ley para la información valiosa considerada de importancia personal, es decir, el derecho fundamental a la libre determinación personal y la competencia de cada uno de disponer sobre la revelación y uso de sus datos personales que, a partir de 1998 constituyen un bien jurídico tutelado. Por lo tanto, es ineludible la relación entre el saber y el poder en este estilo de pleitos. La información, cierta forma del saber, ha cobrado más importancia aún en las relaciones de poder, y se manifiesta en el campo jurídico, a veces denunciándola y puesta al desnudo y a veces justificándolo.

\section{Un derecho personalísimo ${ }^{11}$}

Con respecto a una temática de relevancia para la Argentina, el derecho a la identidad, Travieso (2002) afirma que "en los tratados de derecho humanos, algunos de ellos jerarquizados constitucionalmente, no es posible hallar una norma que se refiera expresamente al derecho a la identidad". Sin embargo, "hay una norma expresa en materia de derecho a la identidad. Se trata de la convención sobre los Derechos Humanos de los Niños" (Travieso, op. Cit.). El derecho a la identidad condensa varios factores del desarrollo humano en sus dimensiones culturales, indicando la singularidad en la biodiversidad del ser humano, que plantea las circunstancias de las diferencias. "No se trata solamente de respetar la alteridad, que implica una simple tolerancia, término que esconde una cierta forma limitativa de la coexistencia, sino que es lo que se denomina la presencia de una otredad, es decir, la existencia de sujetos sociales construidos por otras experiencias humanas" (Travieso; op. Cit.). De tal manera que refugiar este derecho no es sólo limitativo el reconocimiento de la diferencia, sino la obligación estatal de proponer y promover acciones para que determinados sujetos puedan construir su identidad, otra identidad que por ser minoritaria muchas veces no se le otorga posibilidad de ser.

\footnotetext{
${ }^{11}$ A fines didácticos, Ekmekdjian (2002) ordena los derechos consagrados en la C. N. de la siguiente manera: 1) derechos a la dignidad humana y sus derivados (libertad de conciencia, intimidad, a no ser sometido a humillaciones, servidumbres, vejámenes o torturas, etc.); 2) derecho a la vida y sus derivados (derecho a la salud, a la integridad física y psicológica, etc.); 3) derecho a la libertad física; 4) los restantes derechos personalísimos (propia identidad, nombre, imagen, domicilio, etc.); 5) derecho a la información); derecho a la asociación; 7) los restantes derechos personales, primero los derechos fines y luego los derechos medios; 8) los derechos patrimoniales. "Los efectos e implicancias de este orden jerárquico de los derechos civiles son fecundísimos en la hermenéutica jurídica. El principio del índice de restringibilidad relativo puede dar un contenido concreto al art. 28 de la C. N., facilitando el control de razonabilidad. 1) una ley no puede restringir un derecho de rango superior más intensamente que uno de rango inferior. 2) De lo anterior se deduce también que el índice de garantización de un derecho determinado es el límite mínimo del margen de garantización que tiene todo derecho de rango superior al primero".
} 
En 1999 la Corte falló en un caso no haciendo lugar a la impugnación de la paternidad de un menor por parte de una madre en octubre de 1998, esto es, que la madre no pudo comprobar la falta de mérito del padre para ser tutor legal. Sí reconoció la Corte la esencia jurídica del vínculo social de una mujer con su hijo. Aun cuando se consideró que lo biológico acompañó a lo jurídico en este caso, "se afirma la identidad de la madre que establece un vínculo social con su hijo. En consecuencia, se puede afirmar que la Convención sobre la Eliminación de Todas las Formas de Discriminación contra la Mujer, también agrega un plus en cuanto a la identidad de la mujer en la creación de vínculos de la familias" (Travieso, 2002). Sobre este controvertido fallo algunos opinan que aún no se promovieron cambios hermenéuticos, ya que "si la presunción de identidad se establece en función de superadas concepciones patriarcales, entonces, en ese contexto, contrario a los tratados de derechos humanos, no es casual que la madre carezca de legitimidad para impugnar la paternidad del marido" (Spaventa, 2002). Lo controvertido está en el debate que, como bien cita la autora, estuvieron entre quienes negaron la posibilidad a la mujer, como el Juez Belluscio, quien entendió que: "sólo el marido puede valorar la conducta infiel de su esposa, Méndez Costa alegó la supremacía de la paz familiar y social y Zannoni fundamentó la negación en el principio en virtud del cual nadie puede alegar su propia torpeza, es decir, la madre no puede reconocer el adulterio" (Spaventa, op. Cit.). La otra parte, Bidart Campos (2000), Gil Domínguez (2000), Costa y Harari (2000), se basó en el derecho a conocer la realidad biológica y en la igualdad entre varones y mujeres. La mayoría de la Corte en este caso apeló a preservar el valor de "la familia legítima construida como realidad indispensable al bien personal y bien común". ${ }^{12}$ De tal manera, se percibe en este caso un menoscabo en el derecho a la igualdad o una notable discriminación entre varones y mujeres, en lo que atañe al derecho a la identidad.

Con respecto a otro derecho personalísimo es el referido a la identidad sexual. En este tema la jurisprudencia argentina tiene antecedentes de la jurisprudencia europea. "El caso que ad quiere el carácter de leading case es Renee $X$ de 1992, estableciendo el criterio que el Registro Civil debía tener en cuenta ante las peticiones de cambio de sexo de los que hubieran sido sometidos a un tratamiento médico quirúrgico con un objetivo terapéutico, abandonando todos los caracteres de su sexo original. Por otra parte, la exigencia de transformación natural posterior a la operación quirúrgica se abandona a partir de las condiciones siguientes: 1.Condición psíquica. 2. Tratamiento quirúrgico terapéutico. 3. Apariencia física y 4. Comportamiento social. El cumplimiento de estas condiciones consagran la existencia del transexualismo en el derecho actual" (Travieso, 1998). En Argentina, el caso de San Nicolás en 1994 y el caso de Quilmes en 1997, tratan sobre la relación de las posibles interferencias del Estado en decisiones individuales. En el primer caso se trataba de una patología de pseudohermafroditismo, esto es, una malformación que se presenta desde el nacimiento de una persona; en el segundo era una persona nacida hombre que se ha comportado como mujer acreditado esto por numerosas pericias y para completar su acción, se sometió a una intervención quirúrgica fuera de la

12 Considerando 15 del voto de mayoría. Causa CS, 1999/11/01,- D. de P. V., A. c/ O., C. H. (Travieso, 2002, p. 236) 
Argentina. En ambos casos, según Travieso (op. Cit.), se analizaron los antecedentes sociológicos, y de distintas fuentes y luego se hizo lugar a las pericias que acreditaron el comportamiento como mujer del accionante: "Finalmente, se extraen conclusiones que en realidad se hallan fuera de lugar para el decisorio. Tratar sobre las consecuencias que se puedan extraer para el derecho de familia, parecería prejuzgar sobre temas que todavía no se presentaron y en cierta medida pueden determinar un esquema interpretativo que de algún modo pueden limitar el resultado de la sentencia". Es decir, haber colocado la generalidad de un derecho por sobre la especialidad en la interpretación de la norma en estos casos, confirma la fuerte estructura patriarcal de la sociedad. La consideración de la puesta en peligro del derecho a la familia por sobre lo que la realidad individual, social y científica muestra, colocó en zonas oscuras aspectos de la vida cultural en el sistema jurídico. No se permitió accesiblemente- la existencia de nuevas dinámicas sociales que emergen, esta vez, en la configuración de la identidad a través del género.

Las actuaciones de la justicia nacional y provinciales han sido variadas e incluyen novedosos fallos. La tarea del sistema judicial se puede decir que está avanzando en esferas que antaño tenían que ver con la administración pública de los recursos, y con la propia organización social que la población ejerce.

Sin embargo, el Congreso de la Nación Argentina dio un paso a favor de los derechos civiles y en julio de 2010 sancionó la ley 22.618 de matrimonio igualitario el cual, el art. 2 establece que: "es indispensable para la existencia del matrimonio el pleno y libre consentimiento expresado personalmente por ambos contrayentes ante la autoridad competente para celebrarlo. El matrimonio tendrá los mismos requisitos y efectos, con independencia de los contrayentes sean del mismo o diferente sexo." Agrega el texto de ley que en caso de quedar separados por sentencia firme, y en caso de tener hijos el matrimonio constituido por personas del mismo sexo, y en caso de que no existiese acuerdo entre ambos, el juez resolverá la situación teniendo por principal interés al menor. Y en caso de los mayores de esa edad, será el juez quien decida quién es el más idóneo. Para la adopción, la ley establece el mismo derecho para los matrimonios homosexuales o heterosexuales y puntualiza que el adoptado podrá llevar el apellido de los dos cónyuges y, si no hay acuerdo sobre cuál llevar primero se decide por orden alfabético. Y con respecto al apellido del cónyuge, se puede elegir si llevar o no el apellido.

Lo cierto es que se ha construido un discurso apoyado en conocimientos de las ciencias humanas que entran en combate con las fuerzas hasta entonces dominantes. Más allá de que si se legisla a favor o en contra del posible cambio de identidad sexual, de averiguación de la identidad, del matrimonio entre personas del mismo género, del aborto, de la expresión; lo cierto es que siempre está el juego intrínseco de lo que se entiende por verdad, y por lo tanto crea determinados valores sociales, más no tanto en cómo se construye la misma. En algún grupo que germina un conocimiento y demanda por establecerlo, por hacerse reconocer, siempre está ubicado en relación con otro discurso: "Lo importante, creo, es que la verdad no está fuera del poder, ni sin el poder. La 
verdad es de este mundo; está producida aquí gracias a múltiples imposiciones. Tiene aquí efectos reglamentados de poder. Cada sociedad tiene su régimen de verdad, su política general de la verdad: es decir, los tipos de discursos que ella acoge y hace funcionar como verdaderos; los mecanismos y las instancias que permiten distinguir los enunciados verdaderos o falsos, la manera de sancionar unos y a otros; las técnicas y procedimientos que son valorizados para la obtención de la verdad; el estatuto de aquellos encargados de decir qué es lo que funciona como verdadero" (Foucault, 1977a). La verdad sobre el derecho a la identidad, sexual o de la identidad propiamente dicha (o ambos a la vez) en estos casos, es que ha habido múltiples investigaciones científicas que convalidad varios saberes. En relación con el matrimonio entre personas del mismo sexo, en Argentina se vivió un arduo debate acerca de si convertir en ley esta posibilidad civil, en el que los sectores en pugna, tuvieron que desplegar toda su fundamentación de convicciones religiosas, sociológicas, morales, y hasta biológicas. Estos conocimientos han estado en relación directa con la incitación económica y política de una sociedad (la identidad sexual, o el de matrimonio homosexual como problema en una sociedad patriarcal, es un ejemplo de ello). También han sido y son objeto de inmensa difusión y consumo (lo sexual y la identidad) bajo formas diversas, tanto en los medios de comunicación como en las instituciones educativas y también artísticas. De esta manera, regular las verdades sobre estos dos objetos, sobre estas dos temáticas, han sido y es tarea de los aparatos políticos o económicos; mediante las instituciones de prevención y control. Por lo tanto, se reflexiona sobre estas verdades a partir de las lógicas de los enfrentamientos sociales y no sobre el sentido hermenéutico de la verdad por establecer. No queriendo significar con esto que, la verdad de la identidad sexual argentina y el matrimonio heterosexual, carezca de sentido político y social.

\section{Análisis}

Consideramos a estos casos enumerados y descriptos someramente como portadores de todos los factores que hemos venido desarrollando a lo largo de la presente investigación. Esto indica lo determinante que son los órganos internacionales para nuestra organización ética, en términos de justicia penal nacional e internacional. La actuación de las ONGs emergió como muy influyentes para las subjetividades argentinas; determinada aquella por la voluntad de conocer el relato de lo sucedido y demandar la posterior consecuencia jurídica sobre los responsables a los diferentes niveles. El derecho a demandar se hizo con la producción histórica de un saber por parte de grupos organizados, que resistió a la fuerza disciplinante en su expresión totalitaria. La resistencia emergió frente al autoritarismo de la dictadura cívico-militar no pudo ser sino solidaria, denunciante y constante. Coyunturalmente a este saber resistir, se sumó la situación crítica social resumida en estadísticas políticas económicas en cuanto a: la inequitativa distribución del ingreso, el crecimiento del mercado financiero especulativo, la criminalización de la clase social baja, la impunidad del sector de funcionarios públicos y empresarios, la ausencia de actores y recursos estatales, y el aumento de demandas en el sistema judicial de índole social más que de índole penal. 
Son los procesos de subjetivación que se dieron en este contexto el centro de nuestro interés. La cuestión del método de análisis corre por la vigilancia de "desembarazarse del sujeto constituyente, desembarazarse del sujeto mismo, es decir, llegar a un análisis que pueda dar cuenta de la constitución de los saberes, de los discursos, de los dominios de objeto, etc., sin tener que referirse a un sujeto que sea trascendente en relación al campo de los acontecimientos o que corre en su identidad vacía, a través de la historia" (Foucault, 1977a). Lo que se intenta por lo tanto, es de calificar y caracterizar lo que de justo tienen los ciudadanos argentinos de acuerdo con la producción de conocimiento disciplinar que tienen sobre sí. Entre sus soberanías y sus disciplinas, hay todo un despliegue discursivo que evidencia las luchas del poder, que determinan la hermenéutica de nuestra ética, que refieren al uso reflexivo de las propias libertades que elegimos establecer y componer.

Foucault habla del juego de la verdad con rasgos históricos, analizando una economía política de la verdad. Por ejemplo, tanto los que demandan el cambio de identidad sexual, los que acogen e investigan las demandas, los que demandan como objeto de consumo tal configuración; los que criminalizan y sentencian a estas configuraciones de sujeción; los que apresan y controlan, y aquellos opositores que clasifican a una verdad diferente adjetivándola como peligrosa frente a valores como la familia, todos se posicionan desde una política económica de la verdad y no desde una axiología o un conocimiento bien fundamentado. En nuestro caso argentino, los mecanismos de negación y silencio, denuncia y movilización, son condición para muchas de las operaciones de que lo verdadero se establezca. Sin embargo, la sociedad civil, y/o agrupación reconocida simbólicamente, también es un procedimiento necesario, casi obligatorio: es una cuestión de configuración en redes a través de grupos organizacionales con pretensión de verdad. A través de todos estos factores, la economía política de la verdad en los derechos humanos tiene su tiempo, las distintas fuerzas acerca de las concepciones de la identidad, la sexualidad, la identidad sexual, o sobre la familia, se han enfrentado.

Por otro lado, y es el que remarcamos en opinión conjunta con los organismos de derechos humanos, es gracias únicamente a un irrenunciable esfuerzo de los grupos sociales organizados dedicados a la protección de derechos humanos, más un pequeño puñado de jueces en conjunto con la voluntad política, que se pudo avanzar en la investigación de estos delitos: "En fin, la especificidad de la política de verdad en nuestras sociedades. Funciona o lucha a nivel general de éste régimen de verdad tan esencial a las estructuras y al funcionamiento de nuestra sociedad. Existe un combate por la verdad, o al menos alrededor de la verdad -por verdad no quiero decir el conjunto de cosas verdaderas que hay que descubrir o hacer aceptar, sino el conjunto de reglas según las cuales se discrimina como verdadero de lo falso y se ligan a lo verdadero efectos políticos de poder" (Foucault, 1977).

En el orden discursivo, Bidart Campos (1989) dice que el contexto lingüístico de las formulaciones gramaticales en la normativa constitucional equilibra dos principios: el de igualdad de rangos de todas sus normas, y el de la jerarquía 
escalonada de los derechos. Cita este autor a Eusebio Fernández (1984) quien dice: "Es necesario establecer una graduación jerárquica entre los distintos derechos según su importancia, ordenada en relación con la idea de dignidad humana. De todas formas, no olvido que se pueden plantear dificultades $y$ problemas a la hora de evaluar casos concretos y que esta valoración entre derechos responde a las concepciones de filosofía moral, política y jurídica de que se parta". Aún así, Bidart Campos (1989) dice: "si por norma positiva previa se entiende única y necesariamente una norma de reconocimiento de los derechos que se halle formulada por escrito, decimos que esa tal forma no hace falta. Si en cambio admitimos que en el campo del derecho constitucional material hay derecho no escrito cuya normas no constan en una formulación expresa, entonces decimos que por fuente de derecho consuetudinario o de derecho "espontáneo" (no escrito) surge y entra en el derecho constitucional material una norma no formulada por escrito". Si bien estas características no sólo se refieren a lo normativo solamente, sino también a lo informal, o al poder dentro del poder; no impiden por ello analizar y caracterizar, en estos constitucionalistas, las posibilidades y condiciones de construir el saber que en esta materia hay, las economías políticas del comportamiento social e institucional que existen conviviendo con las mismas, y los mecanismos subjetivos que albergan en la experiencia de los derechos humanos en argentina.

\section{Bibliografía}

-BIDART CAMPOS, G. J. (1989): "Teoría general de los derechos humanos". Editorial Astrea. Ciudad de Buenos Aires, 2006.

-CARNOTA, W. (2002): "Enfoques sobre habeas data, operatividad de tratados y retroalimentación internacional. El fallo Urteaga". En TRAVIESO, J. A. (2002): "Colección de Análisis Jurisprudencial. Derechos Humanos y Garantías". La Ley S. A. Bs. As. Argentina. 2002.

-CEPAL (2011): "balance preliminar de las economías de América Latina y el Caribe".

-CELS (2005a): "Colapso del Sistema Carcelario. Temas para pensar la crisis". Siglo XXI Editores Argentina, Buenos Aires.

-CELS (2010): "Derechos Humanos en Argentina. Informe 2010". Siglo XXI Editores S. A., Bs. As. Argentina.

-COSTA, P. M. y HARARI, S. (2000): "Las normas del derechos de familia y la discriminación en razón del género". En "El Derechos en el Género y el Género en el Derecho", Editorial Biblos, Bs. As. 
-EKMEKDJIAN, M. A., (2002): "MANUAL DE LA Constitución Argentina". Ediciones Depalma Buenos Aires.

-FOUCAULT, M. (1977): “Las relaciones de poder penetran en los cuerpos", en Microfísica del Poder. Las Ediciones de La Piqueta, Tercera Edición, 1992. Madrid, España.

-FOUCAULT, M. (1977a): "Verdad y poder", en Microfísica del Poder. Las Ediciones de La Piqueta, Tercera Edición, 1992. Madrid, España.

-GIL DOMINGUEZ, A. (2000): “¿Existe una familia basada en la hipocresía?: la discriminación prevista en el art. 259 del Código Civil y un fallo de la Corte Suprema que llama a la reflexión". La Ley, Suplemento de Derechos Constitucional. Bs. As.

-PALACIO DE CAEIRO, S. B. (2001): "La garantía de la doble instancia y el valor de las recomendaciones de los tribunales internacionales en el proceso penal. El caso Roberto Felicetti -La Tablada-". En TRAVIESO, J. A. (2002): "Colección de Análisis Jurisprudencial. Derechos Humanos y Garantías". La Ley S. A. Bs. As. Argentina. 2002.

-SPAVENTA, V. (2002): "Notas sobre igualdad de derechos a la identidad y a la igualdad de la mujer". En TRAVIESO, J. A. (2002): "Colección de Análisis Jurisprudencial. Derechos Humanos y Garantías". La Ley S. A. Bs. As. Argentina. 2002.

-TRAVIESO, J. A. (1998): "Derechos Humanos y Jurisprudencia. Doctrina y legislación argentina e internacional". Eudeba, Bs. As., Argentina.

-TRAVIESO, J. A. (2002): "Colección de Análisis Jurisprudencial. Derechos Humanos y Garantías". La Ley S. A. Bs. As. Argentina.

\section{Artículo de Revista}

-PARISÍ, E.; MANZI, A. (2012): "Firma de Tratados Internacionales de derechos Humanos en Argentina. Parte I: Modelo neoliberal de los '90. Parte II: Modelo intervencionista (2003-2011)". En Revista NÓMADAS. Número especial América Latina (2012). ISSN 157-6730. Disponible en: http://www.ucm.es/info/nomadas/americalatina2012 